\title{
Characterizing Ethical Decision-Making and Its Influences: Examining Higher Education Leaders in the United States
}

Tara Shollenberger (North Carolina State University)

\section{Introduction}

Previous ethics research has primarily focused on qualities or characteristics that predetermined what was defined as 'good' leadership. To date limited research has focused on how leaders in higher education make ethical decisions. The present research study examined ethical decision-making, specifically how it was defined and its process. Then environmental factors were identified by experts as being influential to the process of EDM within higher education in the United States (U.S.). Finally, experts were asked to create and EDM model that represented EDM in higher education.

No single definition of ethical decision-making has been agreed upon in the related literature. Based on recent reviews there were ten different definitions of ethical decision-making located across the disciplines of ethics, philosophy, business, and education (Barnett 2001; Dubinsky \& Loken 1989; Ethics Resource Center 2009; Jones 1991; Loe, Ferrell, \& Mansfield 2000; Singhapakdi, Vitell, \& Kraft 1996; Tarter \& Hoy 1998; Treviño 1986; Valentine \& Rittenburg 2007; Velesquez et al. 2009). The most common definition was "a process that begins with individuals' recognition that a given action or situation has ethical content and continues as individuals evaluate the action's ethicality, form behavioral intentions and engage in actual behavior" (Barnett \& Valentine 2004, 338). However, definitions tended to minimize or neglect the complexity of the ethical decision-making (EDM) process because it is complex and multidimensional (Beu, Buckley, \& Harvey 2003). In addition, none of these definitions were specific to any academic discipline. Thus, there emerged an important need to identify an ethical decision-making definition that was specific to the field of education which, in turn, might better guide leaders and administrators by providing a clear and concise definition that relates to them instead of the general public.

Not a day goes by where people aren't tempted to compromise their personal beliefs and the ethics codes of organizations due to the pressures of hectic schedules and potential and real conflicts of interest (Shapiro \& Stekfovich 2011). News headlines attested to business and higher education leaders who 'creatively' filed taxes, posted large profits to hide losses and lied to 
the local community, or showed a lack of concern and respect for the internal and external organization stakeholders. Enron, Salomon Brothers, WorldCom, and HIH Insurance first appeared in the media as successful companies with soaring profits only to collapse, affecting thousands of innocent people as a result of unethical leadership. But corporations were not alone in making headlines for ethical miss steps. In 2005, University of Colorado President Elizabeth Hoffman resigned amid allegations of unethical conduct in recruiting prospective student-athletes (de Visé 2011). In 2009, North Carolina State University faced public scrutiny over ethical decisions that led to the firing of Mary Easley, the wife of then Governor of North Carolina (Mildwurf 2009). Also in 2009, University of Illinois President B. Joseph White resigned after it was revealed that he gave special considerations for admission to the sons and daughters of the members of the Board of Trustees, politicians, and members of the administration of former Illinois Governor Rod Blagojevich. In 2011, Penn State President Graham Spanier resigned amid a shocking sexual abuse scandal (de Visé 2011). More recently in 2013, Rutgers University faced an abuse scandal that led to the firing of basketball coach Mike Rice and forced the resignation of Tim Pernetti, the athletic director; the scandal at Rutgers not only cast a negative image for the university but had the potential for significant financial losses amounting to several million dollars (Sherman \& Hayboer 2013).

What leaders should do or the qualities or characteristics they should have to be ethical (Brown \& Treviño 2006) does little to help a leader make good decisions about ethical dilemmas. Rather, a better understanding of the ethical decision-making process that leaders should follow has potential to help them avoid bad behaviors and negative consequences that can result in scandals and worse. Behaviors such as embezzling, collusion, coercion, stealing, political favors, or lying can destroy an organization's reputation and cause pain for many innocent people.

While the large majority of leaders depend on others for their success, unethical leaders act primarily alone (Calabrese \& Roberts 2001). Yet, the EDM literature suggested that there are environmental factors such as social consequences (Barnett 2001), codes of conduct (Barnett \& Vaicys 2000), ethical climate (Singhapakdi, Rao, \& Vitell 1996), and magnitude of consequences (Jones, 1991) that play a critical role in the way leaders make ethical decisions. When leaders were asked about why they acted in an unethical manner, Andrew Fastow, Chief Financial Officer for Enron, described external pressure from Enron stakeholders, and Brad Cooper at HIH Insurance talked about pressure from higher management and stakeholders to falsify records and offer bribes (Di Meglio 2012). Officials at Penn State cited pressure to maintain the reputation of the university as well as not wanting to tarnish the popular and well-known football program as reasons for not reporting sexual abuse (de Visé 2011). Other sports-related scandals have occurred as a 
result of internal and external stakeholder pressures to develop first-rate athletics continue.

The large majority of research on the EDM of leaders was carried out within a context of for-profit business. To date, research has not focused on non-profit or governmental organizations such as universities. For example, no studies have been published on high profile ethical scandals like the recent Penn State University case. This is unfortunate because leaders in higher education have a 'higher' and more transparent ethical responsibility than other leaders due in part to the increasingly important role that higher education is taking to positively influence individuals, organizations, and societies, as well as the impact that international growth of educational institutions is having on leadership (Shapiro \& Stefkovich 2011). The ethical decision-making process that administrators use not only affects them personally, but it can also impact staff, faculty, students, parents, communities, and the overall ethical climate of the organization (Starrat 2004) and can even have an impact on communities and societies (Hatcher \& Aragon 2000). Ethical decision-making is not simply the procedure used by a leader to make a decision; it is the process by which human values are put into action. In the present study, ethical decision-making of higher education leaders in the U.S. were examined. The U.S. was chosen as a research site based on higher education scandals like that of North Carolina State University, the University of North Carolina, Penn State University, and others for their unethical practices which affected millions of people and highlighted the need for ethical standards. For example, the scandal at Penn State was cited as one of the reasons for the $7 \%$ or $\$ 7.8$ million decline in revenue for the Penn State athletic department in 2012 (Armas 2013), supporting the need for a closer examination of ethical standards within the U.S. higher education context.

\section{Models}

Several response process models were constructed to help leaders gain insights into the complexity of EDM (Sen \& Vinze 1997). Of the models developed, the following six models are the most referenced EDM models located in the related literature. All these models were developed within the field of business to examine concepts such management, sales, and marketing. These six models have been established and validated and have been used and cited in other fields of academia beyond the business field; however, it is important that a model be developed that is specific to higher education and the unique challenges that pertain to that field. The six models are: 1) The Four Component Model (Rest 1986), 2) Contingency Model of Ethical Decision Making in a Marketing Organization (Ferrell \& Gresham 1985), 3) Model for Analyzing Ethical Decision-Making in Marketing (Dubinsky \& Loken 1989), 4) Model of Ethical Decision Making (Hunt \& Vitell 1986), 5) Issue-Contingent 
Model of Ethical Decision Making in Organizations (Jones 1991), and 6) Interactionist Model of Ethical Decision Making in Organizations (Treviño 1986).

Each of the six models is slightly different in make-up which reflects differences in leaders' perspectives. After examination of the aforementioned models, the following ten components were identified as important. The ten components are: (1) recognition of the ethical issue (Ferrell \& Gresham 1985; Hunt \& Vitell 1986; Jones 1991; Rest 1986; Treviño 1986), (2) stages of moral development (Jones 1991; Rest 1986; Treviño 1986), (3) environmental factors (internal) (Ferrell \& Gresham 1985; Hunt \& Vitell 1986; Jones 1991; Treviño 1986), (4) environmental factors (external) (Ferrell \& Gresham 1985; Hunt \& Vitell 1986; Jones 1991; Treviño 1986), (5) individual moderators (Ferrell \& Gresham 1985; Hunt \& Vitell 1986; Jones 1991; Treviño 1986), (6) moral intensity (Jones 1991), (7) evaluation of behavior (Dubinsky \& Loken 1989; Ferrell \& Gresham 1985, Hunt \& Vitell 1986; Jones 1991; Rest 1986); (8) moral decision-making (Ferrell \& Gresham 1985; Jones 1991; Rest 1986), (9) engagement in moral behavior (Dubinsky \& Loken 1989; Ferrell \& Gresham 1985; Hunt \& Vitell 1986; Jones 1991; Rest 1986; Treviño 1986), and (10) consequences (Dubinsky \& Loken 1989; Ferrell \& Gresham 1985; Hunt \& Vitell 1986; Jones 1991).

\section{Statement of the Problem}

Treviño and Youngblood (1990) found that something within the organizational environment misleads otherwise good employees to exhibit unethical behaviors supporting the need for experts as defined by the Delphi method to identify important environmental factors that impact ethical decision-making (see Figure 1). Previous EDM research found significance in individual variables such as gender, age, personality, and cultural. These variables while important expose a significant gap in the literature in reference to environmental influences on ethical decision-making practices. Environmental influences are variables unlike gender and age, which can be manipulated and are constantly changing. This creates a hardship on employers as these are not static variables. This gap is even more apparent within the context of higher education. More needs to be understood about environmental influences on the processes used to make ethical decisions. Currently, there are multiple EDM process models identified in the literature. The six most referenced models were developed and used within business and industry. No EDM process model was located that was developed or used in higher education.

If leaders better understand the cause-and-effect specific components are having on their decisions on how to address ethical dilemmas, then those decisions may result in positive results that have the potential to nurture an 
ethical work environment (Treviño \& Youngblood 1990). In addition, if environmental factors are identified, these variables can be critical for leaders who work in multi-cultural environments. Therefore, this study examined the various definitions of EDM in order to identify a specific definition that applies to the field of higher education. Additionally, this study identified environmental factors that influence the EDM processes used by university leaders in the U.S. Finally, an EDM process model was refined and developed and agreed upon by leaders in the U.S. Creating a new process of ethical decision-making which can be used with each specific population rather than relying on a model that was created for a different area.

\section{Theoretical Framework}

For the purpose of this study, both middle-range and substantive theories were used to establish the theoretical framework. Creswell (2009) describes a middle-range or meso-level theories that link the micro and macro level theories. A middle-range or meso-level is defined as theories of organization, social movement, or community, and macro level theories are defined as providing explanations for larger institutions like social institutions, cultural systems, or whole societies. Substantive theories, on the other hand, "offer explanations in more restricted settings and are limited in scope, often being expressed as propositions or hypotheses" (Camp 2001, 3) for example, as used in case studies. In addition, Bartlett $(2003,225)$ states that "the lack of a coherent theoretical framework which is able to embrace the complexities of organizational reality at these multiple levels of analysis constitutes a problem for the field in terms of (...) ethical research and theorizing." Therefore, several substantive theories were proposed as theoretical frameworks which were used to guide this study in an attempt to embrace the complexities of the reality of ethical decision-making. However, using a Delphi study limits the generalization of findings, thus offering a more limited scope as in the case of a substantive theory.

The first proposed substantive theory was categorized as 'Socialization and Learning'. Socialization supports the importance of the organizational or business environment (Schein 1990). Specifically, for this research study socialization explains environmental factors and how those factors interact within a business environment, for example, when a business leaves candy out in the break room. If an employee takes any candy they leave money for it next to the candy. Everyone in the business observes this behavior and follows this accepted culture. Learning as a theoretical framework is synthesized from the theories of social learning and the power of context. Learning supports the importance of how people teach, learn, and model other people and environments (Bandura 1977), in this specific instance, work environments. Learning couples with Socialization in explaining environmental factors within 
a business environment. To continue the example from above, if an employee starts taking candy without paying and no consequences are put in place, any employee that observes this behavior learns that it must be okay and also starts taking the candy without paying. Socialization and Learning explain how environmental factors like leaving the candy out create a situation for employees to learn good or bad behaviors within a work environment. In addition, decision-making theory was used as a theoretical framework. Decision-making supports the purposeful process, through which action or thought is strategized, implemented, and evaluated (Tarter \& Hoy 1998).

In being able to describe what influences leaders in ethical decisionmaking, there is literature that points to socialization and learning. Socialization describes the organizational culture whereas social learning theory and the power of context describes how an individual learns from other people or their environment. Given the complex nature of human interactions, emotions, and characteristics, social learning theory helps describe how people learn skills; gain abilities, attitudes, and values; and pass ideas from person to person (Morris \& Maisto 1998). The 'Power of Context' (Gladwell 2000) adds another dimension to social learning theory to explain how individuals may learn from those in their surrounding like parents, sisters, brothers, teachers, role models, etc., but individuals also learn from the physical environment. The surrounding environment can be just as important to a person's behavior in any given situation as can be the factors that influenced them. Finally, decisionmaking theory was also introduced to understand the reasoning and process that people engage in when confronted with a condition that requires a decision. It is for that reason that socialization and learning are key contributors in helping to describe what influences leaders in ethical decisionmaking and that decision-making theory contributes to the process of ethical decision-making?

\section{Research Questions}

The study was exploratory in nature using a review of literature and the Delphi method to collect and synthesize expert knowledge through an Internet-based data collection format. In addition, the Delphi method was used to create a new model of EDM. Three research questions guided the study. The research questions were used to 1) identify how ethical decision-making was defined by leaders in higher education within U.S. universities and 2) to identify top environmental factors they felt were important. The third research question asked participants to develop an EDM model using 10 pre-established components from the EDM literature and come to a consensus on a new process model they believed was important in carrying out ethical decisionmaking for higher education administrators. 


\section{Research Question 1}

To what extent was there a consensus on a definition of ethical decision-making among a Delphi panel of subject matter experts (SMEs) representing leadership in higher education in the U.S.?

\section{Research Question 2}

Was there consensus on the top environmental factors that they believed important for ethical decision-making among the Delphi panel of experts representing leadership in higher education in the U.S.?

\section{Research Question 3}

Was there consensus among the Delphi panel of experts representing leadership in higher education in making choices about identifying and connecting the multiple process components of ethical decision-making models, and if no consensus was reached what differences in choices of model components existed?

\section{Methods}

\subsection{Delphi Method}

The Delphi method is a strongly structured group communication process, on which naturally unsure and incomplete knowledge is available and is judged upon by experts (Cuhls 2011). A Delphi study aims to achieve an agreed upon consensus of opinion by conducting two or more rounds of intensive surveys using self-identified 'experts' in ethical decision-making by using anonymity and controlled feedback (Clayton 1997). The Delphi method was selected because it is 'structured communication' method among experts which sets future directions for a given topic or field per the opinion of subject-matter experts (Helmer 1975; Loo 2002) in order to "support judgmental or heuristic decision-making, or more colloquially, creative or informed decision-making" (Ziglio 1996, 3). This is the first time in which the Delphi method is being used to study ethical decision-making.

Using the research questions, three Delphi questions were created for each research question. The type of question was created based on the research question and a review of other Delphi studies for historical reference. A small pilot study was conducted before sending the survey to the subject matter experts (SME). The Delphi method used SME to define and characterize ethical decision-making of higher education administrators. SMEs then examined and came to consensus about the top environmental factors that were believed to influence ethical decision-making. Finally, they synthesized ten pre-identified components from six different established ethical decisionmaking processes and then used them to build a 'new' conceptual model. 


\subsection{Population and sample}

After obtaining IRB approval participants for this study were identified using a review of literature of EDM for the (see Table 1). Using the step-by-step criteria, 24 participants which were ranked in the top tier were identified and 16 in the second tier for a total of forty prospective participants. Originally, participants were contacted in the Summer of 2013 to participate in this study. During that time the researcher received a lot of feedback that participants were unavailable due to travel, research, and established summer plans as only three participants agreed to participate. The study was then postponed until the Fall of 2013. At the beginning of September 2013 the participants were each contacted again via email to participate. It was indicated that the study would begin at the end of September. If a participant was not able to join the study the researcher asked the participant for a recommendation in the field. It was observed that people were more responsive after receiving an email that they were suggested by another person in the field. After one week, an attempt was made by phone to reach individuals who did not respond. As panel members agreed to become a part of the Delphi study, required consent forms were collected. This time around three participants from tier one and four from tier two agreed to participate for a total of seven participants.

\section{Results}

The following section is a review and discussion of the results based on the data collected during the research process.

\subsection{Participants}

There were seven participants for round one, six participants for round two, and five participants for round three of the Delphi method. Table 2 contains the demographic information including participants' ages and gender for all three rounds. The majority of participants were 36 years or older and female.

\subsection{Results by research question}

The following are results of the study per each of the research questions. Each research question includes final results and discussion of participant responses.

\subsubsection{Research question 1}

Rounds 1 and 2. The means of the ethical definitions are reported in Table 3 for the U.S. subject matter expert group. The U.S. group acknowledged that Definitions 2 and 3 best described their definition of ethical decision-making. In addition, one participant from the U.S. group provided an additional definition available in Table 4. After asking the U.S. participants to rank Definitions 2, 3, 
and the additional definition for a total of three definitions, definition 3 which was added by the subject matter expert was ranked most favorable.

Final Round. In the final round however, definition 2, "a process that begins with an individual's recognition that a given action or situation has ethical content and continues as individuals evaluate the actions ethically, from behavioral intentions and engage in actual behavior" was ranked as the top ethical decision-making definition. In the final round participants were asked to provide additional feedback. Three participants commented specifically on the final definition of EDM. The comments included, "recognizes internal and external factors involved that influence the process," "it explicitly covers the various components in what I conceptualize as a process," and "complicating or confounding this individual process is the recognition of individual differences in moral reasoning, locus of control, cognitive moral development, and perceptions of moral intensity. This definition also acknowledges that despite the individual level perspective of moral reasoning, situational influences can alter individual behavior. Good people can do bad things under some situations. Never underestimate the power of the situation (be it peer pressure, rewards/punishments, or leader influences)."

General comments by SMEs included, "I don't think situational influences change ethics. I think they change decisions, but they don't change the fundamental ethical stand point of the individual. A person who perceives that is unethical to steal may be driven by situational factors to steal, but they will need to provide rationalizations for these actions - they will not suddenly maintain the ethical perspective that it is OK to steal."

\subsubsection{Research question 2}

Rounds 1 and 2. The means for environmental factors that influence ethical decision-making are provided in Table 5 and 6 for the U.S. panel experts.

Final Round. Final environmental factors that are ranked as most influential by U.S. experts were rewards (30\%) and behavior of superiors (30\%) tied for first. Second was peer pressure (17\%), and third was norms $(10 \%)$ and corporate culture $(10 \%)$ ). SME reasoning for these factors includes, "these three factors that touch an individual's life most closely, while ethical climate and corporate culture are more vague influences that create an atmosphere in which actions take place." Other comments by SMEs included: "the one at the top matters nearly as much, and probably sets the ethical climate and corporate culture anyway," "I don't see these are being necessarily separate factors. I think that norms are communicated to individuals by the behavior or those who are perceived to hold high status, and that these individual in turn create an ethical climate for the unit of organization in which they hold status," "The social information processing view of the workplace acknowledges the influence of peers. People pay attention to their coworkers and how they will be judged and treated by coworkers. Go along, don't rock the boat is very 
seductive to most individuals. Second, people pay attention to authority figures, especially when they control rewards and punishments. Hence, rewards followed by superiors' behavior. The history of WorldCom and Enron tells us that folks pay attention to authority. 'I was simply following orders' is a common explanation for why otherwise good people are doing time in a U.S. Federal Prisons," and "The basic motivator in an organization is the reward system which explicitly sets the rewards and sanctions for behaviors. These expectations are then modulated by the actual behavior of superiors and the pressure to respond to peer."

\subsubsection{Research question 3}

The final research question asked each SME to create a new EDM process model using components from a review of 10 EDM models. In the first round, using the ten predetermined components provided to the U.S. SMEs, only 3 out of 7 participants submitted models. Therefore in round two, participants were asked to rank all the models. Originally, if all participants had submitted a model the researcher would have synthesized and combined like models. However, since so few participants submitted models, all models were included. SMEs were asked to rank all models, with a rank 1 being the one that best described the process that most closely resembled their personal ethical decision-making and 3 being the one that least described their personal ethical decision-making process. Table 7 shows the results from rounds 2 and 3 for the U.S. panel. Component 2 (see Figure 1) was the model with the highest percentage (53\%) after panel experts ranked the models. One SME justified the choice by saying, " 2 is the more complex, and may well represent the process better." However, some of the comments by panel experts show some apprehension with each model, "While both models include the key components, it seems to me the second model is unnecessarily complex. It may in fact be a better representation, but would be difficult to communicate. I think the simpler model illustrates the process more clearly," and "Model two lacks parsimony and is unnecessarily complicated. I don't see an individual's ethical perspective being altered by everything under the sun; I regard it as a more steady-state element that can be subtly altered at times, but that the frequent alterations implied by model 2 are unlikely." One participant who selected component 2 seemed undecided:

"Component 2, which I do not completely agree with, comes closer to capturing the direct, indirect, and moderating influences of factors that influence individual ethical decision-making and behavior. Component 1 assumes that environment only influences awareness. People know sometimes that they are being asked to violate their own ethical principles. Yet, they do just this. This is why we call it a moral or ethical dilemma. Their values clash with those of the organization. So, recognition of the ethics is not the issue. How to resolve the conflict is the issue and environmental 
factors influence the choice of action to take to resolve the dilemma, as well."

Finally, one participant conveyed the following message:

"The influences are messy - having impact on steps in the process of awareness to actual behavior. For example, in the [Boston] Marathon Bombing case, the external examples of terrorism provoke an awareness of the option to set off a bomb in a public place, and the very size and distraction of the crowd provides the anonymity to accomplish the task. In the case of $9 / 11$, the terrorists on the flight were not able to accomplish their goal because the external influence of the other passengers prevented them."

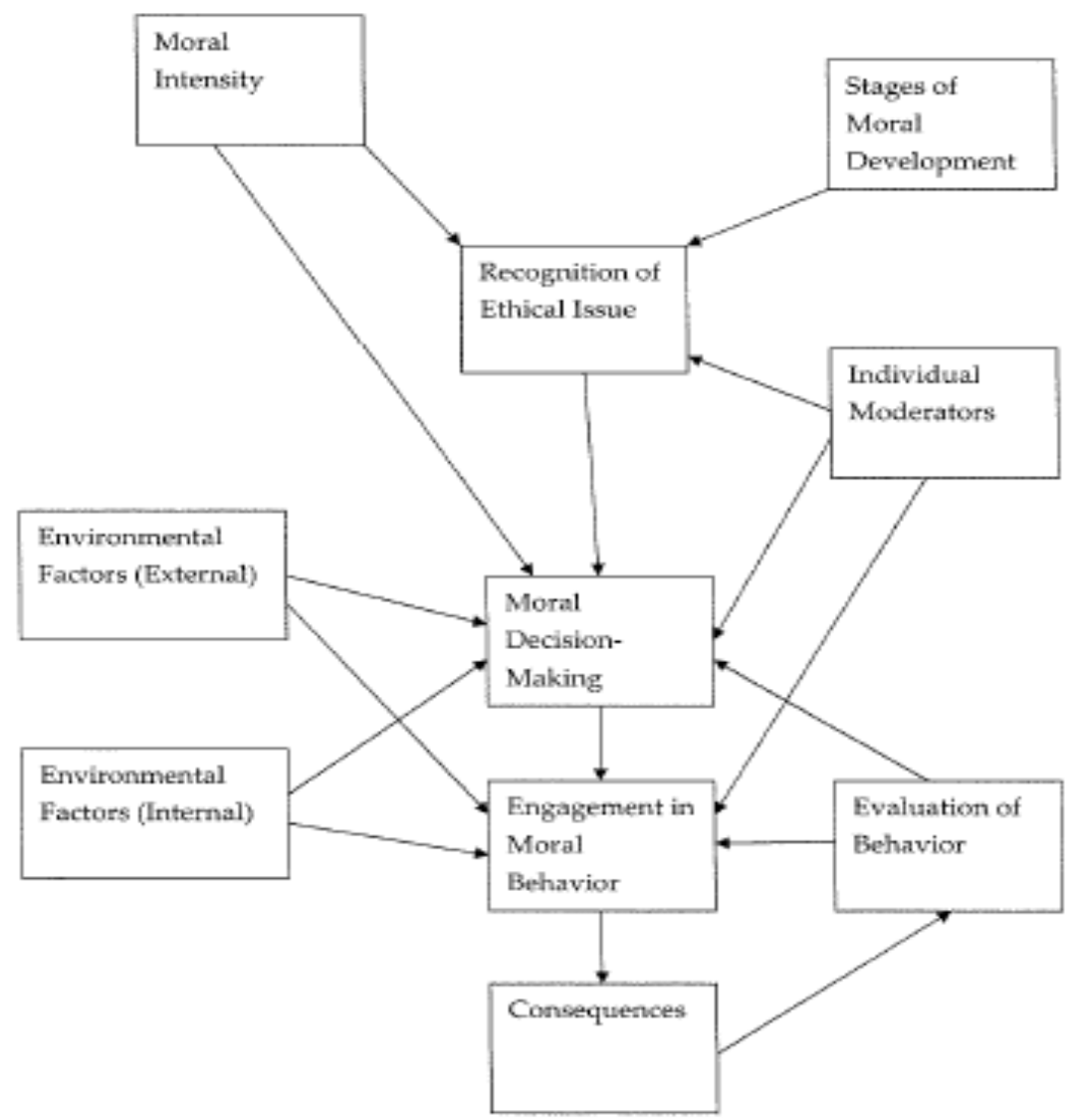

Figure 1. U.S. Delphi Expert Ethical Decision Making Model

\section{Conclusions}

The present study was exploratory in nature and was carried out with a group of SMEs in ethics in higher education in the U.S.: a) define ethical decision- 
making within higher education, b) identify environmental factors that were deemed important to ethical decision decision-making, and c) use the Delphi research method to create an ethical decision-making process model applicable for use in higher education.

Prior to this research study, there was not a common definition of EMD, and there was limited research on the environmental factors that influenced ethical decision-making. Little research was located that focused on ethical decision-making within higher education. Yet, as this study suggested educational leaders have a greater ethical responsibility than do other leaders (Shapiro \& Stefkovich, 2011). Thus, how leaders make ethical decisions becomes a critical part of the organization. Further, ethical scandals are no longer confined to within U.S. corporations. Many recent scandals in higher education have demonstrated the impact that ethical scandals have on an institution.

\subsection{Research question 1}

A thorough literature review revealed a lack of consensus on or an agreed upon definition of ethical decision-making. The review of literature resulted in identifying nine different definitions that were then presented to Delphi expert panels. Results suggested that experts can, in fact, come to a consensus about how EDM should be defined. The chosen definition of the experts was: "a process that begins with an individual's recognition that a given action or situation has ethical content and continues as individuals evaluate the actions ethically, from behavioral intentions and engage in actual behavior." This definition was originally developed by Dubinsky and Loken and published in the Journal of Business Research in 1989. The characteristic of this definition as compared to the other definitions is that this definition discusses the process of EDM and the individual recognition and behavior. In addition, this definition has immediate practical applicability. This definition shows that the panel thought of ethical decision-making as a process which was a reoccurring theme in the comments provided by the expert panel. In addition, experts felt that environmental factors do not have a strong influence; rather people have a change in decisions not ethical values. Compared to this definition, other definitions found in the literature are an incomplete description of the EDM process because they discuss a process but not the recognition of an ethical situation or outcome behavior. For example, Barnett's (2001) definition defines EDM as: a process that must be triggered by the perception that a given action has a moral or ethical component that should be evaluated, showing that EDM is a process but not referencing anything about the recognition of the ethical dilemma or outcome. Some definitions discuss the recognition and behavior of EDM but not the process such as Jones (1991): a decision that is both legal and morally acceptable to the larger community. 


\subsection{Research question 2}

In regards to environmental factors, the literature provided a list of factors that is considered important, but the expert panels were able to narrow those lists down to select variables that can be further examined in future research studies. The focus of this research was to explore the ethical decision-making process and the environmental factors that were identified as important. There was a consensus within each group on environmental factors, but each panel identified different environmental factors as influential. The U.S. panel narrowed down the list to the following six factors that they felt influence ethical decision-making: behavior of supervisors, rewards of systems, peer pressure, norms, corporate culture, and ethical climate. These environmental factors speak to the culture within U.S. organizations and how important organizational culture is. It supports the perceptions that the U.S. culture is work driven and highly influenced by an organizational culture, thus highlighting the importance for an organization to understand how influential work culture can be on an individual and at times more influential than societal norms. This outcome supports the research of Treviño and Youngblood (1990) that states influences within a work environment are important because they can influence individuals to make bad decisions, and leads to the conclusion that employers need to be aware of environmental factors and influences within their organization because these factors can be more influential to their employee than social norms.

\subsection{Research question 3}

The U.S. panel created a model (see Figure 1) that was very complex and multidimensional in nature. The model is a continual process of evaluation and re-evaluation as can be seen by the process model arrows that create a continuous process. There is neither a clear defined beginning nor a process of steps or stages that a person goes through, but rather a complex web of choices and influences that the experts indicate to be ongoing. This is observed to be consistent with U.S. culture. Americans are often viewed as 'multi-taskers' or always juggling various commitments. Given this dynamic an EDM model that accounts for daily complex, fast-paced, and multi-faceted aspects in decisions is expected.

The model developed by the U.S. participants is not similar to any of the six established EDM models. Each of these six models is constructed with a very linear and step-by-step process. The U.S. model has no clear beginning and is very inter-related. Now that model has been created a future study can examine if the model is valid and/or actually reflects the population for which it was meant.

\subsection{Implications for research and practice}


This research adds to the conceptual understanding of ethical decision-making on several levels. Prior to the present study very little was available on EDM and higher education. Now, an EDM definition for the field of higher education has been identified. The identification of an EDM definition can lead practitioners in higher education in establishing guidelines for EDM centered around this definition within their institutions.

Research on environmental factors across all fields was scarce. Experts were able to identify top environmental factors that they felt can influence ethical decision-making. From a practical perspective this information can help leaders identify areas or people within an organization that perhaps foster or have these characteristics and can be addressed early before a scandal happens. Additionally, it was identified that different environmental factors were deemed influential by SMEs.

\subsection{Recommendations for future research}

Overall recommendations by this researcher for utilizing the data in this study include: help organizations identify/audit for behavior of supervisors, reward systems, and corporate culture in the U.S. that could influence employees in their ethical decision-making. Ethical decision-making factors will also allow administrators to evaluate seriousness of consequences in organizations so that they detract from unwanted behaviors. Lastly, future recommendations include taking both ethical decision-making models from the U.S. and validating them through more quantitative measures so that they can be used on a more global scale within both countries.

With regards to the unique way in which the Delphi method was used, it begs the question what other types of research the Delphi method can be used for. Previously used primarily as a survey tool, this research demonstrates that the Delphi methodology can be used for other research inquiries. Furthermore, it should challenge other researchers to see what other uncommon methods could be used in similar research. Being able to think in a creative way can open the door to innovative research techniques and allow for more insightful research.

From this discussion, some additional research questions may include the following: 1) How do environmental factors compare within different age groups of ethical 'experts'?, 2) Can follow up interviews of the 'expert' panelists provide additional information not shared throughout this process?, 3) How can further quantitative processes be used to validate the models created by the expert panels?, and 4) the models created in the present research still need to validated. 


\section{References}

Armas, G. C. 2013. Penn State's Revenue Takes a Dive Following Jerry Sandusky Sex Abuse Scandal. URL: http://www.huffingtonpost.com/2013/04/11/penn-states-revenuetakes-dive_n_3064258.html.

Bandura, A. 1977. Social Learning Theory. Upper Saddle River, NJ: Prentice-Hall, Inc.

Barnett, T. 2001. "Dimensions of Moral Intensity and Ethical Decision-Making: An empirical study." Journal of Applied Social Psychology 31(5): 10381057. doi: 10.1111/j.1559-1816.2001.tb02661.x.

Barnett, T. \& Vaicys, C. 2000. “The Moderating Effect of Individuals' Perceptions of Ethical Work Climate of Ethical Judgments and Behavioral Intentions." Journal of Business Ethics 27(4): 351-362. doi: 10.1023/A:1006382407821

Barnett, T. \& Valentine, S. 2004. "Issue Contingencies and Marketers' Recognition of Ethical Issues, Ethical Judgments and Behavioral Intentions." Journal of Business Research 57(4): 338-346. doi: 10.1016/S0148-2963(02)00365-X.

Bartlett, D. 2003. "Management and Business Ethics: A Critique and Integration of Ethical Decision-Making Models." British Journal of Management 14(3): 223-235. doi: 10.1111/1467-8551.00376.

Beu, D. S., Buckley, M. R., \& Harvey, M. G. 2003. "Ethical Decision-Making: A Multidimensional Construct." Business Ethics: A European Review 12(1): 88-107. doi: 10.1111/1467-8608.00308.

Brown, M. E. \& Treviño, L. K. 2006. "Ethical Leadership: A Review and Future Directions." The Leadership Quarterly 17(6): 595-616. doi: 10.1016/j.leaqua.2006.10.004.

Calabrese, R. L. \& Roberts, B. 2001. "The Promise Forsaken: Neglecting the Ethical Implications of Leadership." The International Journal of Educational Management: 15(6), 267-275. doi: 10.1108/09513540110401475.

Camp, W. G. 2001. "Formulating and Evaluating Theoretical Frameworks for Career and Technical Education Research." Journal of Vocational Education Research 26(1): 1-13. doi: 10.5328/JVER26.1.4.

Clayton, M. J. 1997. "Delphi: A Technique to Harness Expert Opinion for Critical Decision-Making Tasks in Education." Educational Psychology 17(4): 373-386. doi: 10.1080/0144341970170401.

Colton, S. \& Hatcher, T. 2004. "The Web-Based Delphi Research Technique As a Method for Content Validation in HRD and Adult Education Research." Paper presented at the meeting of Academy of Human Resource Development International Research Conference, Austin, TX. 
Creswell, J. W. 2009. Research Design: Qualitative, Quantitative, and Mixed Methods Approaches. Los Angeles, CA: Sage Publications.

Cuhls, K. 2011. Delphi Method. Retrieved from United Nations Industrial Development Organization web site. URL: http://www.unido.org/fileadmin/import/16959_DelphiMethod.pdf.

de Visé, D. 2011. Eight Scandals That Ended College Presidencies [Blog post]. Retrieved from The Washington Post Blogs. URL: http://www.washingtonpost.com/blogs/college-inc/post/eightscandals-that-ended-college-presidencies/2011/11/21/gIQA4diYiN_ blog.html.

Di Meglio, F. 2012. Enron's Andrew Fastow: The Mistakes I Made. Retrieved from Business Week. URL: http://www.businessweek.com/articles/ 2012-03-22/enrons-andrew-fastow-the-mistakes-i-made.

Dubinsky, A. J. \& Loken, B. 1989. "Analyzing Ethical Decision-Making in Marketing." Journal of Business Research 19(2): 83-107. doi: 10.1016/0148-2963(89)90001-5.

Ethics Resource Center. 2009. Ethics Glossary. URL: http://www.ethics.org/resource/ethics-glossary.

Ferrell, 0. C. \& Gresham, L. G. 1985. "A Contingency Framework for Understanding Ethical Decision-Making in Marketing." Journal of Marketing 49(3): 87-96.

Hatcher, T. \& Aragon, S. R. 2000. "A Code of Ethics and Integrity for HRD Research and Practice." Human Resource Development Quarterly: 11(2): 179-185. doi: 10.1002/1532-1096(200022)11.

Helmer, 0. 1975. "Forward." In: Linstone, H. A. \& Turnoff, M. (Eds.) The Delphi Method: Techniques and Applications. Reading, MA: Addison-Wesley: xix$\mathrm{xx}$.

Hunt, S. D. \& Vitell, S. 1986. "A General Theory of Marketing Ethics." Journal of Macromarketing 6(1): 5-16. doi: 10.1177/027614678600600103.

Jones, T. M. 1991. "Ethical Decision-Making By Individuals in Organizations: An Issue-Contingent Model." The Academy of Management Review 16(2): 366-395.

Loe, T. W., Ferrell, L., \& Mansfield, P. 2000. "A Review of Empirical Studies Assessing Ethical Decision Making in Business." Journal of Business Ethics 25(3): 185-204.

Loo, R. 2002. "The Delphi Method: A Powerful Tool for Strategic Management." Policing 25(4): 762-769. doi: 10.1108/13639510210450677.

Mildwurf, B. 2009. N.C. State Fires Mary Easley. Retrieved from WRAL.com. URL: http://www.wral.com/news/local/story/5307783/.

Morris, C. G. \& Maisto, A. A. 1998. Psychology: An Introduction. Upper Saddle River, NJ: Prentice Hall.

Rest, J. R. 1986. Moral Development: Advances in Research and Theory. New York: Praeger. 
Schein, E. H. 1990. “Organizational Culture.” American Psychologist 45(2): 109119. doi: 10.1037/0003-066X.45.2.109.

Sen, A. \& Vinze, A. S. 1997. "Understanding the Complexity of the Model Formulation Process: A Protocol Analysis Approach." Decision Sciences 28(2): 443-473. doi: 10.1111/j.1540-5915.1997.tb01318.x.

Shapiro, J. P. \& Stefkovich, J. A. 2011. Ethical Leadership and Decision-Making in Education: Applying Theoretical Perspectives to Complex Dilemmas. New York: Routledge.

Sherman, T. \& Heyboer, K. 2013. Rutgers Basketball Scandal Could Have Negative Effect on School's Credit Rating, Agency Says. Retrieved from NJ.com. URL: http://www.nj.com/news/index.ssf/2013/04/rutgers_ basketball_scandal_cou.html.

Singhapakdi, A., Rao, C. P., \& Vitell, S. J. 1996. "Ethical Decision-Making: An Investigation of Services Marketing Professionals." Journal of Business Ethics 15(6): 635-644. doi: 10.1007/BF00411798.

Singhapakdi, A., Vitell, S. J., \& Kraft, K. L. 1996. "Moral Intensity and Ethical Decision-Making of Marketing Professionals." Journal of Business Research 36(3): 245-255. doi: 10.1016/0148-2963(95)00155-7.

Starratt, R. J. 2004. Ethical Leadership. San Francisco, CA: Jossey-Bass.

Tarter, C. J. \& Hoy, W. K. 1998. "Toward a Contingency Theory of DecisionMaking." Journal of Educational Administration 36(3): 212-228. doi: 10.1108/09578239810214687.

Treviño, L. K. 1986. "Ethical Decision-Making in Organizations: A PersonSituation Interactionist Model." The Academy of Management Review 11(3): 601-617.

Treviño, L. K. \& Youngblood, S. A. 1990. "Bad Apples in Bad Barrels: A Casual Analysis of Ethical Decision-Making Behavior." Journal of Applied Psychology 75(4): 378-385. doi: 10.1037/0021-9010.75.4.378.

Valentine, S. R. \& Rittenburg, T. L. 2007. "The Ethical Decision-Making of Men and Women Executives in International Business Situations." Journal of Business Ethics 71(2): 125-134. doi: 10.1007/s10551-006-9129-y.

Velesquez, M., Moberg, D., Meyer, M. J., Shanks, T., McLean, M. R., DeCosse, D., \& Hanson, K. O. 2009. A Framework for Thinking Ethically. Retrieved from Santa Clara University Website. URL: http://www.scu.edu/ethics/practicing/decision/framework.html

Ziglio, E. 1996. "The Delphi Method and Its Contribution to Decision-Making." In: Adler, M. \& Ziglio, E. (Eds.) Gazing Into the Oracle: The Delphi Method and Its Application to Social Policy and Public Health. Bristol, UK: Jessica Kingsley Publishers: 3-33. 
Appendix

\begin{tabular}{|c|c|c|}
\hline Step & Procedure & Result \\
\hline Step 1 & $\begin{array}{l}\text { Review literature to compile a } \\
\text { list of potential panel members } \\
\text { based on recent book or journal } \\
\text { articles. }\end{array}$ & $\begin{array}{l}\text { Compile list of names for } \\
\text { 'expert' panelists. }\end{array}$ \\
\hline Step 2 & $\begin{array}{l}\text { Check books or articles (or other } \\
\text { articles or books by the same } \\
\text { author) for evidence of } \\
\text { knowledge of desired topic area. }\end{array}$ & $\begin{array}{l}\text { Mark for evidence of desired } \\
\text { topic area. }\end{array}$ \\
\hline Step 3 & $\begin{array}{l}\text { Evaluate potential experts as to } \\
\text { their contributions to the } \\
\text { scholarly discussion of desired } \\
\text { topic. }\end{array}$ & $\begin{array}{l}\text { Rate potential experts on a } \\
\text { suitability-to-the-study scale of } 1 \\
\text { to } 3(1=\text { not useful, } 2= \\
\text { moderately useful, } 3=\text { very } \\
\text { useful to the study). }\end{array}$ \\
\hline Step 4 & $\begin{array}{l}\text { Telephone or email each } \\
\text { potential panel member to } \\
\text { explain the purpose and scope } \\
\text { of the study, with invitation to } \\
\text { participate. }\end{array}$ & $\begin{array}{l}\text { Follow-up with each participant } \\
\text { committed to the study with } \\
\text { letter and consent forms. }\end{array}$ \\
\hline
\end{tabular}

Table 1. Procedure for selection of panel experts ${ }^{1}$.

\begin{tabular}{llll}
\hline Variables & $\begin{array}{l}\text { \% of Sample } \\
\text { Round 1 }\end{array}$ & Round 2 & Round 3 \\
\hline Age & 0 & 0 & 0 \\
$18-25$ & 0 & 0 & 0 \\
$26-30$ & 100 & 100 & 100 \\
$36+$ & & & \\
Gender & 43 & 33 & 40 \\
Male & 57 & 67 & 60 \\
Female & & & \\
\hline
\end{tabular}

${ }^{1}$ Adapted from Colton \& Hatcher (2004). The web-based Delphi research technique as a method for content validation in HRD and adult education research. Paper presented at the meeting of Academy of Human Resource Development International Research Conference, Austin, TX. 
Table 2. U.S. demographic characteristics for all three rounds ${ }^{2}$.

\begin{tabular}{|c|c|c|}
\hline Definition & Mean & S.D. \\
\hline $\begin{array}{l}\text { A process that must be triggered by the perception that a } \\
\text { given action has a moral or ethical component that should } \\
\text { be evaluated. }\end{array}$ & 2.14 & .69 \\
\hline $\begin{array}{l}\text { A process that begins with an individual's recognition that } \\
\text { a given action or situation has ethical content and } \\
\text { continues as individuals evaluate the actions ethically, } \\
\text { from behavioral intentions and engage in actual behavior }\end{array}$ & 1.29 & .76 \\
\hline $\begin{array}{l}\text { Not a simple and straightforward process but instead it is } \\
\text { complex and multi-dimensional. }\end{array}$ & 2.00 & 1.30 \\
\hline $\begin{array}{l}\text { A decision that is both legal and morally acceptable to the } \\
\text { larger community }\end{array}$ & 2.86 & .69 \\
\hline $\begin{array}{l}\text { Making good ethical decisions requires a trained } \\
\text { sensitivity to ethical issues and a practiced method for } \\
\text { exploring the ethical aspects of a decision and weighing } \\
\text { the considerations that should impact our choice of a } \\
\text { course of action. Having a method for ethical decision- } \\
\text { making is absolutely essential. When practiced regularly, } \\
\text { the method becomes so familiar that we work through it } \\
\text { automatically without consulting the specific steps. }\end{array}$ & 3.00 & 1.00 \\
\hline $\begin{array}{l}\text { An integrative process that is influenced by counselors' } \\
\text { personal character and virtue, cognitive abilities, and } \\
\text { decision-making skills which promotes sound solutions to } \\
\text { ethical dilemmas }\end{array}$ & 3.43 & .53 \\
\hline $\begin{array}{l}\text { Ethical Decision Making Process is the process of choosing } \\
\text { the best alternative for achieving the best results or } \\
\text { outcomes compliance with individual and social values, } \\
\text { moral, and regulations. }\end{array}$ & 2.43 & 1.27 \\
\hline $\begin{array}{l}\text { Absolute standard of judgment to a social standard, based } \\
\text { on cultural, organizational, or community standards }\end{array}$ & 3.28 & .76 \\
\hline $\begin{array}{l}\text { Rational, deliberate, purposeful action, beginning with the } \\
\text { development of a decision strategy and moving through } \\
\text { implementation and appraisal of results }\end{array}$ & 2.57 & .79 \\
\hline
\end{tabular}

2 Round One N=7, Round Two N=6, and Round Three N=5. 
Table 3. U.S. leaders' definitions of EDM and descriptive statistics for Delphi3.

\begin{tabular}{lcc}
\hline Definition & $\begin{array}{c}\text { Round } \\
\text { Two } \\
\mathbf{\%}\end{array}$ & $\begin{array}{c}\text { Round } \\
\text { Three } \\
\mathbf{\%}\end{array}$ \\
\hline $\begin{array}{l}\text { A process that begins with an individual's recognition that } \\
\text { a given action or situation has ethical content and }\end{array}$ & .31 & .80 \\
$\begin{array}{l}\text { continues as individuals evaluate the actions ethically, } \\
\text { from behavioral intentions and engage in actual behavior }\end{array}$ & & \\
$\begin{array}{l}\text { Not a simple and straightforward process but instead it is } \\
\text { complex and multi-dimensional. }\end{array}$ & .23 & -- \\
$\begin{array}{l}\text { EDM at individual level begins with awareness, followed by } \\
\text { judgment, then intention, then action or behavior. }\end{array}$ & .46 & .20 \\
$\begin{array}{l}\text { Complicating this process are both situational influences } \\
\text { and individual differences. }\end{array}$ & & \\
\hline
\end{tabular}

Table 4. U.S. Definitions Round 2 and Round 3 percentage votes ${ }^{4}$.

\begin{tabular}{lcc}
\hline Environmental Factor & Mean & S.D. \\
\hline Seriousness of consequences & 1.57 & .53 \\
Social consequences & 1.71 & .49 \\
Proximity & 1.86 & .69 \\
Rewards Systems & 1.29 & .76 \\
Norms & 1.43 & .53 \\
Codes of Conduct & 2.43 & .79 \\
Organizational Climate & 1.29 & .49 \\
Ethical Climate & 1.43 & .53 \\
Magnitude of consequences & 1.57 & .53 \\
Social Consensus & 1.86 & .69 \\
Temporal immediacy & 1.86 & .69 \\
Probability of effect & 1.71 & .49 \\
Cultural & 1.57 & .53 \\
Peer Pressure & 1.86 & .69 \\
Management Influence & 1.71 & .76 \\
Organizational Size & 2.86 & .90 \\
Organizational Level & 3.14 & .69 \\
Industry Type & 3.29 & .76 \\
Business Competitiveness & 2.14 & .38 \\
Risk & 2.14 & .38 \\
Opportunity & 1.86 & 1.07 \\
\hline & & \\
\hline
\end{tabular}

${ }^{3}$ Round One $\mathrm{N}=7$.

${ }^{4}$ Round $2 \mathrm{~N}=6$; Round $3 \mathrm{~N}=5$. Percentages based on total participants ranking of each definition for round 3 . 


\begin{tabular}{lcc}
\hline Sanctions & 1.71 & .76 \\
Societal values & 2.00 & .82 \\
Humanistic values & 2.29 & 1.25 \\
Corporate goals & 2.43 & .79 \\
Stated Policy & 3.00 & .82 \\
Corporate culture & 1.43 & .53 \\
Licensing requirements & 2.57 & .53 \\
Professional Meetings & 3.29 & .49 \\
Peer Group & 1.86 & .38 \\
Family & 3.29 & .76 \\
Legislation & 2.29 & .79 \\
Judicial System & 2.43 & .79 \\
Taxation & 2.57 & .79 \\
Financial Needs & 2.29 & .76 \\
Behavior of Superiors & 1.43 & .53 \\
\hline
\end{tabular}

Table 5. Environmental factors identification and descriptive statistics for U.S. leaders: Round One ${ }^{5}$.

\begin{tabular}{lll}
\hline Environmental Factor & Round Two \% & Round Three \% \\
\hline Ethical Climate & .16 & .03 \\
Behavior of Superiors & .16 & .30 \\
Rewards Systems & .08 & .30 \\
Norms & .08 & .10 \\
Peer Pressure & .08 & .17 \\
Corporate Culture & .08 & .10 \\
Peer Group & .04 & -- \\
Seriousness of consequences & .04 & -- \\
Social consequences & .04 & -- \\
Organizational Climate & .04 & -- \\
Magnitude of consequences & .04 & -- \\
Probability of effect & .04 & -- \\
Opportunity & .04 & -- \\
Societal values & .04 & -- \\
Corporate goals & .04 & -- \\
Proximity & .04 & -- \\
Social Consensus & .00 & -- \\
Temporal immediacy & .00 & -- \\
Cultural & .00 & -- \\
Management Influence & .00 & -- \\
Business Competitiveness & .00 & -- \\
\hline
\end{tabular}

${ }^{5} \mathrm{~N}=7$. 


\begin{tabular}{lll}
\hline Risk & .00 & -- \\
Sanctions & .00 & -- \\
\hline
\end{tabular}

Table 6. U.S. Environmental factors per Round Two and Round Three - percentage votes ${ }^{6}$

\begin{tabular}{lcc}
\hline Environmental Factor & Round 2 \% & Round 3 \% \\
\hline Component 1 & .34 & .47 \\
Component 2 & .43 & .53 \\
Component 3 & .23 & -- \\
\hline
\end{tabular}

Table 7. U.S. component Round Two and Round Three ${ }^{7}$.

${ }^{6}$ Round $2 \mathrm{~N}=6$; Round $3 \mathrm{~N}=5$. Percentages based on total participants ranking of each definition for round 3 .

7 Round $2 \mathrm{~N}=6$; Round $3 \mathrm{~N}=5$. Percentages based on total participants ranking of each component for round 2 and round 3. 
Tara Shollenberger (North Carolina State University)

\title{
Characterizing Ethical Decision-Making and Its Influences: Examining Higher Education Leaders in the United States
}

\begin{abstract}
The ethical decision-making (EDM) process that leaders should follow to avoid scandals and unethical behavior is often overlooked. In addition, few studies have focused on EDM within higher education. Yet, educational leaders have an ethical responsibility due in part to increasingly diverse student populations enrolled that is having an impact on the growth of educational institutions. This exploratory study used the Delphi research technique to identify an EDM definition that leaders use to make ethical decisions and identify the environmental factors that influence their decisions as well as an EDM model within the U.S.
\end{abstract}

Keywords: Study examines ethical decision-making definitions, environmental factors and models within higher education.

Ethics in Progress (ISSN 2084-9257). Vol. 6 (2015). No. 1, pp. 50-73.

doi: 10.14746/eip.2015.2.5 